\title{
EDUCAÇ̃̃O BÁSICA EM TEMPOS DE PANDEMIA: PADRONIZADA, REMOTA, DOMICILIAR E DESIGUAL
}

\author{
Thiago Colmenero Cunha ${ }^{\mathrm{i}}$ \\ Isabel Scrivano ii \\ Erick da Silva Vieiraii
}

\begin{abstract}
Resumo: O presente manuscrito tem por objetivo discutir como as estratégias de educação remota implementadas nas redes estadual e municipal de ensino do Rio de Janeiro funcionam como ferramentas de acirramento das desigualdades sociais e educacionais durante o tempo de isolamento social imposto como forma de evitar o contágio pela COVID-19. Para apresentar como isso se efetiva no cotidiano escolar em tempos pandêmicos, utiliza-se como dispositivo de análise entrevistas com profissionais de educação sobre o ensino remoto padronizado adotado nas referidas redes de ensino. Por fim, problematizamos a discussão sobre uma estratégia considerada inevitável no momento: uma (im)possível educação domiciliar por parte das famílias.
\end{abstract}

Palavras-chave: COVID-19; Desigualdade social; Educação básica; Educação domiciliar; Ensino remoto.

\section{BASIC EDUCATION IN PANDEMIC TIMES: STANDARDIZED, REMOTE, AT HOME AND UNEQUAL}

\begin{abstract}
This manuscript aims to discuss how education strategies remotely implemented in the state and municipal education systems of Rio de Janeiro work as tools that hardens social and educational inequalities during the time of social isolation imposed as a way to avoid contagion by COVID -19. To disclose how it works in school life in pandemic times, the article analyzes interviews with education professionals about the standardized remote teaching adopted. Finally, it problematizes a discussion about a strategy considered inevitable at the moment: an (im)possibility of homeschooling by families.
\end{abstract}

Key-words: COVID-19; Social inequality; Basic education; Homeschooling; Remote teaching.

\section{Introdução}

Imagine a seguinte cena: em uma rápida busca na internet, o catálogo de produtos disponível para compra parece interminável, seguindo por páginas e páginas de resultados. Como escolher com tantas opções disponíveis? Que critérios utilizar: marca, duração, quantidade e/ou qualidade do conteúdo, preço - será possível pensar em custo-benefício? Sempre, é o que dizem. Só não é permitido desperdiçar tempo, afinal, fazer parte de uma geração de profisssionais perdidos ${ }^{\mathrm{iv}}$ não é sequer cogitável. Adiciona-se no carrinho; dados de 
pagamento e de parcelamento são informados; compra concluída. O melhor de tudo: não há prazo de entrega. O pacote é disponibilizado tão logo o pagamento seja confirmado, ao alcance de uma sequência curta de clicks, sem precisar sair das quatro paredes de um quarto.

Em outro conjunto de paredes, o roteiro é outro: a conexão de internet não é uma realidade constante, e os equipamentos que podem ser utilizados são compartilhados por toda uma família. A escolha é em que momento do dia cada integrante terá chance de acesso - e, certamente, fazer compras não é um dos motivos para tanto. Cotidianamente, o consumo deste produto dá-se de outras formas, de fato fora das paredes ou em outras - nem pode ser assim caracterizado, já que muitas vezes somente com ele o acesso a outros bens é possível.

Talvez o cenário comum proposto seja aplicável a muitos produtos; talvez educação não pareça uma possibilidade. Talvez. Contudo, pensar o processo educacional enquanto produto não é uma novidade, principalmente na medida em que, transformada em objeto de um mercado que não para de crescer, a demanda nunca se esgota e, portanto, a oferta tem de abarcá-la a todo o tempo. Mas então, o que é a novidade?

Fenômeno de três sílabas e tônica longe do fim: uma pandemia, anunciada oficialmente em 11 de março pela Organização Mundial de Saúde (OMS), da doença denominada COVID-19, cujo agente etiológico consiste em um novo tipo de coronavírus $(\mathrm{Sars}-\mathrm{CoV}-2)^{\mathrm{v}}$. Sem tratamento específico ou medicamento descoberto, um dos focos de ação tem sido a implementação de medidas de prevenção à disseminação do vírus, sendo o distanciamento social a mais eficaz para tal objetivo, além do uso de máscaras e higiene pessoal constante. Neste cenário, as aulas foram suspensas, da educação básica ao nível superior, e os governos federal, estaduais e municipais convocados a definir planos de ação baseados nas realidades de suas comunidades e, principalmente, reavaliar as políticas educacionais em curso em vistas de construir estratégias possíveis.

No âmbito federal, as medidas adotadas contemplam: a substituição das aulas presenciais por aulas em meios digitais enquanto durar a situação de pandemia (BRASIL, 2020a); o estabelecimento de normas excepcionais sobre o ano letivo da educação básica e do ensino superior, permitindo tanto a flexibilização da quantidade de dias, desde que cumprida a quantidade de oitocentas horas prevista na Lei de Diretrizes e Bases, como também a modalidade de ensino remoto para o cômputo destas (BRASIL, 2020b); alterações na execução do Programa Nacional de Alimentação Escolar - PNAE, com a previsão de disponibilização de kits de gêneros alimentícios às/aos estudantes e suas famílias, operacionalizada pelas gestões locais; além da ampliação do escopo de multiprogramação de entidades executoras de serviço de radiodifusão de sons e imagens em tecnologia digital com 
conteúdo específico destinado à atividades de educação (BRASIL, 2020d) e premissas acerca das aulas nos cursos de educação profissional técnica de nível médio (BRASIL, 2020c).

Já no contexto do estado do Rio de Janeiro, cuja quantidade de casos e óbitos confirmados em decorrência da COVID-19 lhe conferem a segunda posição em levantamento nacional (87.317 e 8.412, respectivamente, até 19 de junho de 2020), as aulas permanecem suspensas desde o dia 16 de março, após quatro prorrogações do prazo inicial de quinze dias. Em atendimento às deliberações do Conselho Estadual de Educação - $\mathrm{CEE}^{\mathrm{vi}}$, que estabelecem termos para o cômputo das atividades remotas como parte da carga horária através da manutenção do calendário escolar vigente, a Secretaria Estadual de Educação do Estado do Rio de Janeiro (SEEDUC-RJ) afirma como estratégias a disponibilização de aulas online através da plataforma Google Classroom e a programação educativa especial na TV Futura às/aos alunos/as que não tiverem acesso à internet, a SEEDUC aponta, em suas redes sociais, o envio de material impresso.

Para além dos distintos modos de implementação das diretrizes nacionais por parte das secretarias estaduais e municipais de educação ${ }^{\text {vii }}$, o que chama a atenção para a discussão que aqui propomos é o compartilhamento de uma estratégia considerada inevitável no momento da crise: fazer da casa - e, portanto, da família - o espaço educacional possível para que as premissas supracitadas sejam atendidas. Observa-se o discurso do vírus enquanto inimigo invisível, que convoca a união de todas/os para ser vencido, como fundamento de ações para que a vida não pare e, com ela, o processo educacional de 47,9 milhões de estudantes brasileiras e brasileiros (BRASIL, 2020e).

Contudo, é a partir da rejeição de tal discurso que nossas análises acerca da pandemia enquanto acontecimento e sua relação com as políticas educacionais se constroem e, em consonância com Valdete Souto Severo (2020), defendemos uma perspectiva baseada nas materialidades em termos de escolhas, individuais ou sociais - mas sempre políticas -, estas sim conduzindo-nos até o presente momento. Desse modo, indagações tomam lugar de destaque: que racionalidades operam na concepção da casa como espaço de educação? Que processos de escolhas - e de quem - podem ser constatados nesse jogo complexo de forças de produção de subjetividades e que efeitos são produzidos?

Em vistas de pensar as realidades produzidas, é imprescindível ter como ferramenta uma metodologia que não objetifique e estanque os fenômenos estudados em uma natureza ou uma essência. É então através do método cartográfico de pesquisa (MORAES, 2010; PASSOS, KASTRUP, ESCÓSSIA, 2015) que temos por objetivo acompanhar os processos 
que trazem à tona as lógicas de poder e o jogo de forças agenciados por meio das políticas educacionais adotadas em tempos de pandemia e isolamento social.

Concebendo a entrevista enquanto ferramenta metodológica (TEDESCO, SADE, CALIMAN, 2014), convidamos profissionais da educação em níveis de direção, coordenação e docência, atuantes no município e/ou no estado do Rio de Janeiro, a compartilharem suas percepções acerca dos impactos das medidas adotadas no processo educacional e nos agentes que o compõem, principalmente sobre como os processos educacionais vêm sendo alterados na escola, com as/os trabalhadoras/es, com as/os estudantes. Aposta-se na entrevista não apenas como escuta de informações, isto é, do conteúdo do dito, mas como acesso à experiência em suas múltiplas dimensões. As entrevistas foram realizadas após o consentimento livre e esclarecido das/dos participantes - aprovado pelo parecer CEP/CONEP - CAAE n ${ }^{\mathrm{o}} 31673314.7 .0000 .5582$ - e de maneira remota em plataformas de comunicação - e não de educação, diga-se de passagem - com o uso de vídeo chamadas e ligações, mediadas por um roteiro semiestruturado com perguntas abertas.

Deste modo, é tomando as realidades de escolas públicas do estado e do município do Rio de Janeiro e das/dos protagonistas que as constituem - e fazendo de seus posicionamentos, modos e possibilidades de atuação e produção nossa bússola ética - que apresentamos questões e problematizamos estes cotidianos tão próximos e imediatos, mas ignorados pelos gestores e secretários na implementação das medidas. Nesse mapa de questões, as falas destas/destes profissionais constituem o dispositivo de análise, dada sua produção enquanto máquina que faz ver e falar racionalidades (DELEUZE, 1996) e os agenciamentos que as enunciam.

Destaca-se os intercessores e a política de escrita aqui construída, cuja importância se afirma através da inserção das e dos participantes que aparecerão durante esse manuscrito: sejam elas e eles professoras/es, gestoras/es da escola, mães, pais, apostamos em suas vozes enquanto figuras de referência para conversar e escrever junto, escrever com. Assim, as frases, casos, contextos e analisadores, muitas vezes citados literalmente através da escrita em itálico (sinalizando que alguma das/dos personagens da pesquisa disse exatamente aquilo), serão trazidos ao longo do manuscrito.

Esse processo de trazer outras epistemologias para conversar, debater e dialogar sobre os atuais conflitos encontrados nessas escolas frente à pandemia configura-se como entendimento de que esse processo de desmonte da gestão da escola pública e sua transformação em meras reprodutoras da aprendizagem-padronizada proposta por institutos e empresas privadas de educação já vinha causando a precarização do ensino-aprendizagem e 
acirrando as desigualdades sociais e educacionais das/dos estudantes matriculadas/os nessas escolas. No atual momento de isolamento social por conta da epidemia de COVID-19, o cenário se agrava ainda mais e a politização desses conflitos - a partir de contextualizações territoriais, raciais, econômicas, sociais e de classe - é necessária, fundamentada nas materialidades que estes ensejam, ou seja, o acirramento de desigualdades estruturais.

\section{As faces da educação remota em tempos pandêmicos como ferramenta de acirramento das desigualdades}

A partir dos anos 1990, o neoliberalismo começa a ser implementado no Brasil e, inevitavelmente, realiza reformas no campo econômico, político e educacional. Pablo Gentili em texto de 1996 já alertava para o fato de que

(...) a grande operação estratégica do neoliberalismo consiste em transferir a educação da esfera da política para a esfera do mercado questionando assim seu caráter de direito e reduzindo-a a sua condição de propriedade, [...] através de uma revalorização da ação do indivíduo enquanto proprietário, enquanto indivíduo que luta para conquistar (comprar) propriedadesmercadorias diversa índole, sendo a educação uma delas (p. 14).

Nesse mesmo período, as secretarias de educação do estado e do município do Rio de Janeiro - e em grande parte do país - começaram a implementar e definir políticas que visam transformar as salas de aula em um lugar de atuação automática e burocrática. A relação ensino-aprendizagem foi cedendo lugar para a aprendizagem-padronizada, ou seja, retirandose de cena a valorização das diferentes estratégias de ensino utilizadas pelas/os professoras/es para produção de conhecimento e as possibilidades de debate e de produção de subjetividades singularizadas $^{\text {viii }}$, ou seja, a posição da instituição escolar em permitir às/aos estudantes uma construção de si através de experiências diversas da preocupação homogeneizante 'apenas' com o polo da aprendizagem para o mercado de trabalho.

Na rede municipal do Rio de Janeiro, lenta e sutilmente as escolas passaram a receber projetos prontos fruto de convênios e/ou acordos entre secretarias de educação e fundações privadas. No início os referidos projetos eram voltados para aplicação em turmas formadas especificamente para atendimento de um determinado público, como por exemplo as formadas por alunas/os com distorção idade-série ${ }^{\mathrm{ix}}$. Com o passar do tempo as parcerias foram aumentando, cartilhas prontas e padronizadas para todas as turmas de todos os anos/séries e de todas as escolas da rede municipal passaram a ser adotadas, fazendo com que estas se preocupassem com metas pré-determinadas que deveriam ser atingidas, melhoradas 
ou mantidas, como o Índice de Desenvolvimento da Educação Básica (IDEB) por exemplo, e com provas de avaliação de desempenho como a Prova Brasil e a Avaliação Nacional de Alfabetização (ANA).

Como consequência dessa transformação na gestão da política pública de educação em que gestores que não conhecem a realidade de cada comunidade escolar pré-determinam o que e como se deve ensinar e avaliar a aprendizagem, professoras/es passaram a ser vistas/os como meros aplicadores de apostilas e métodos prontos e culpabilizados pelos baixos índices alcançados em metas e avaliações, nos quais estudantes e suas famílias passaram a ser cada vez mais coagidos ao enquadramento no modelo hegemônico reconhecido como positivo e, ainda mais, para aqueles que não se enquadraram restou o rótulo do fracasso escolar e/ou a culpabilização/penalização com um encaminhamento ao conselho tutelar, ao sistema de saúde para atendimento psicológico, neurológico, psiquiátrico.

Nessa perspectiva, segundo a educadora Maria Helena Souza Patto (1992, 2015), a produção do "fracasso escolar" tende a ser concebido como resultante de obstáculos - sejam eles classificados como afetivos, orgânicos, culturais, familiares - que marcam o sujeito, considerando-o de maneira isolada. As relações todas que acontecem dentro da escola, por sua vez, tendem a ser vistas em abstração do entorno institucional em que ocorrem e dos condicionantes políticos e ideológicos que sobre elas incidem.

Não obstante seu caráter vago, esse tipo de diagnóstico tem sido um poderoso elemento no processo de legitimação do suposto caráter individual do "fracasso escolar" e no ocultamento de suas raízes sociais e escolares. Ainda mais grave, ele acaba sendo construído junto do próprio rótulo do "aluno-problema", na medida em que existe justamente por inscrever uma profecia, algo como uma fatalidade inevitável. Neste sentido, optamos por dizer de um "fracasso da escola" (PAIXÃO, 2003), pois retira o caráter individual que o termo "fracasso escolar" carrega, com o objetivo de realizar uma leitura institucional e política acerca das questões apresentadas pelos indivíduos no espaço escolar (BOTELHO, CUNHA, BICALHO, 2020).

Segundo dados do último Censo da Educação Básica, realizado no ano de 2019 e disponibilizado pelo Instituto Nacional de Estudos e Pesquisas Educacionais Anísio Teixeira (INEP), o estado do Rio de Janeiro tem aproximadamente 3,5 milhões de alunos/as matriculados na educação básica e a maioria na rede pública de ensino. São 1.681 .988 alunos na rede municipal, 739.583 na rede estadual, 40.114 na rede federal e 1.111 .732 na rede privada. 
No que se refere às políticas educacionais circunscritas ao estado do Rio de Janeiro frente à pandemia, tem-se acompanhado movimentos tanto na Assembleia Legislativa do Estado do Rio de Janeiro (ALERJ), com a criação de um Observatório de Educação Remota, para acompanhamento das medidas tomadas frente à pandemia, assim como os sindicatos das classes dos trabalhadores de educação pública do estado, o Sindicato dos Professores do Município do Rio de Janeiro e Região (Sinpro-Rio) e o Sindicato Estadual dos Profissionais da Educação do Rio de Janeiro (Sepe-RJ) se posicionando de maneira contrária às medidas tomadas pois aprofundariam extremas desigualdades sociais devido ao fato de não existir estrutura e material para acessar as plataformas solicitadas.

A pesquisa TIC Domicílios 2019, divulgada em 26 de maio, produzida pelo Centro Regional de Estudos para o Desenvolvimento da Sociedade da Informação (Cetic.br) vinculado à Organização das Nações Unidas para a Educação, a Ciência e a Cultura (UNESCO) relata que o Brasil tem 134 milhões de usuários de Internet, o que representa 74\% da população com 10 anos ou mais. Contudo, mesmo com o amplo crescimento nos últimos anos de acordo com o número de habitantes que usam a internet, cerca de um quarto dos indivíduos (47 milhões de pessoas) seguem sem acesso a este direito fundamental. Pelo recorte socioeconômico, enquanto $95 \%$ das casas da classe A possuem algum tipo de computador, eles estão presentes em apenas 44\% das habitações da classe C e 14\% das residências das classes D e E. As atividades de comunicação são as mais comuns no uso da rede, sendo o envio de mensagens instantâneas realizado por $92 \%$ dos usuários de Internet, seguido pelo uso de redes sociais (76\%) e chamadas por voz ou vídeo (73\%), em crescimento nos últimos anos. Alexandre Barbosa, gerente do Cetic.br, em matéria de divulgação da pesquisa no próprio site do Centro resume bem a situação em que se encontram milhares de brasileiros (as) diante do isolamento social.

Com o isolamento social, medida de prevenção a Covid-19, milhões de brasileiros passaram a depender ainda mais da Internet e das TIC de maneira geral para realizar atividades de trabalho remoto, ensino à distância e até mesmo para acessar o auxílio emergencial do governo. Mas a falta de acesso à Internet e o uso exclusivamente por celular, especialmente nas classes DE, evidenciam as desigualdades digitais presentes no país, e apresentam desafios relevantes para a efetividade das políticas públicas de enfrentamento da pandemia. A população infantil em idade escolar nas famílias vulneráveis e sem acesso à Internet também é muito afetada neste período de isolamento social. A pandemia revela de forma clara as desigualdades no Brasil (CGI.BR, 2020).

Com esse cenário posto, percebemos entendimentos e atuações distintas nas redes públicas de ensino presentes no estado do Rio de Janeiro. As escolas públicas federais, por 
serem autarquias com autonomia administrativa, patrimonial, financeira, didático-pedagógica e disciplinar (BRASIL, 2008), constituíram comitês de emergência para discutir os protocolos internos e definir ações que seriam incorporadas à rotina de trabalho dos campi, o que levou à suspensão dos calendários acadêmicos e atividades presenciais de ensino, além de não adotar o ensino remoto visando a promoção da educação pública, gratuita e de qualidade e a igualdade de condições de acesso para todas e todos as/os estudantes.

Por outro lado, a Secretaria Estadual de Educação do Estado do Rio de Janeiro (SEEDUC-RJ) e a Secretaria Municipal de Educação (SME), que adotam decisões verticalizadas e não levam em conta a realidade da maioria dos alunos/as - fenômeno já apontado em levantamentos anteriores à pandemia acerca do uso das tecnologias nos sistemas públicos brasileiros (IWASAKI et al, 2020) - implementaram o que está sendo chamado atualmente de Ensino Remoto que

(...) assemelha-se à Educação a Distância $(\mathrm{EaD})$ apenas no que se refere a uma educação mediada pela tecnologia. Mas os princípios seguem sendo os mesmos da educação presencial. [...] EaD envolve um desenho institucional próprio; material didático adequado, pensado para esta modalidade; formação docente específica para ministrar cursos a distância; metodologia das aulas própria da modalidade, assim como dos exercícios e avaliações; existência de equipes de apoio acadêmico e técnico; plataforma adequada; atividades assíncronas - eventualmente também síncronas - e, via de regra, encontros presenciais previstos no calendário letivo (APG-UFRJ, 2020, p. $30)$.

Para além de uma discussão terminológica, o comentário do participante da pesquisa Tadeu $^{\mathrm{x}}, 38$ anos, professor de sociologia da rede estadual fluminense há seis anos, sobre o ensino denominado remoto pelas secretarias reflete o sentimento de vários professores e professoras entrevistados/as: o máximo que posso chamar é de exercício e monitoramento a distância, pois passo deveres e tarefas e fico aqui corrigindo. Isso não é ensinar. O que temos é uma embromação.

Tendo crianças e adolescentes como público da unidade escolar, abarcando Ensino Fundamental I e Fundamental II, a diretora Áurea, 48 anos, educadora no ensino público da Zona Norte do município há 30 anos, se indaga: como vamos fazer ensino remoto por redes sociais com crianças em processo de alfabetização? Essa também é a preocupação da diretora Kelly, 40 anos, há 18 anos trabalhando como professora: Não existe ensino a distância pro ensino fundamental, eles dizem que o nome disso é ensino remoto. Sabemos que não estamos alcançando nem metade da escola com essas atividades, mesmo com os professores se disponibilizando e a gente sendo cobrado sem parar. Educação precisa de encontro físico, 
ela é socioafetiva, não há aprendizagem sem afeto. Estamos só aumentando a desigualdade e produzindo mais miséria assim, isso não é educação.

Uma das profissionais da coordenação conta que escreveu para a gerente de educação da sua Coordenadoria pedindo ajuda, procurando encontrar caminhos possíveis de serem traçados para tentar não descumprir o que estava sendo proposto nem aumentar as desigualdades educacionais históricas já existentes entre os que podem ter acesso e os que não têm acesso a nada, como o público majoritariamente atendido pela unidade escolar. Relata que foi respondida com a mensagem: "entendo sua angústia, mas tudo é muito novo para todos, inclusive para nós aqui também. Sua escola está no caminho certo, fazendo o que é possivel, com quem der e se der".

Letícia, 34 anos, professora do município há sete anos e coordenadora de uma escola da Zona Norte do Rio de Janeiro, relata que sua equipe escolar continua suas funções e atividades trabalhando de casa, mantendo o distanciamento social e que o primeiro trabalho encaminhado pela SME, encarregado pela direção da escola, foi a entrega de um número limitado de cartões de alimentação para determinadas famílias, escolhidas por critérios de vulnerabilidade social. Relata ainda que a escola fez uma arrecadação entre as/os profissionais e a comunidade escolar para doar cestas básicas às famílias que também passavam fome e necessidades básicas, mas que não foram contempladas pela iniciativa do governo federal. Atitude que demonstra que é impossível para educadoras/es implicadas/os ${ }^{\mathrm{xi}}$ e que sofrem com as desigualdades e imposições verticalizadas e descontextualizadas das secretarias de educação "fazer com quem der e se der", ou seja, torna-se frequentemente uma tarefa a mais para educadoras(es) encontrar meios de não deixar ninguém para trás, de garantir direitos fundamentais como alimentação e educação para todas/os.

O caminho de comunicação comumente usado desde março na rede municipal e na rede estadual vem sendo: a Secretaria envia os materiais por e-mail à direção que tem a responsabilidade de fazer chegar a cada responsável e a cada criança, sendo proposto através das redes sociais WhatsApp ou Facebook de cada estudante ou de cada responsável. Dessa forma, é recomendado que os responsáveis imprimam as tarefas para que seus filhos e suas filhas façam, para que depois a/o docente possa corrigir junto com eles. A equipe de preparação de materiais didáticos da SME vem mandando atividades diárias e materiais complementares para as/os estudantes sobre interpretação e soluções de problemas cotidianos relacionados à atual pandemia e ao coronavírus, vinculados aos conteúdos programáticos recomendados para o ano/série. O material traz questões cotidianas, como interpretação de texto, notícias sobre COVID-19, jogos e passatempos. Por meio de um site da prefeitura, 
ficam armazenados, além dos materiais semanais, as apostilas utilizadas na rede de ensino e outros links para outros sites da própria prefeitura, como a MultiRio ${ }^{\text {xii }}$, por exemplo.

A diretora Silvana, 51 anos, há 20 anos educadora de uma unidade escolar da Zona Sul do Rio de Janeiro se posiciona: quantos entraves nessa política feita pra dar errado! E as famílias que não tem internet? E os responsáveis que não estão no grupo de WhatsApp da turma do seu filho? E as famílias que não estão no WhatsApp ou no Facebook? Como essas atividades de fato chegarão aos estudantes? Bento, 38 anos, há 17 anos como docente, professor da Zona Oeste do município, também comenta sobre esse tema: Uma constatação flagrante de que o ensino não deu certo, pela própria Secretaria de Educação, e agora a saida é enxugar gelo pelo WhatsApp. É contraditório dizer que ensinar pelo WhatsApp está dando certo, não é possível, até pela nossa posição como educadores e educadoras $O$ que estamos fazendo não é nem ensino remoto, é contato e controle remoto!.

Durante o mês de abril de 2020, a equipe de coordenação e direção de uma escola municipal da Zona Norte do estado fez levantamento e pesquisas sobre as medidas que a SME-RJ vem implantando sobre como os materiais didáticos transmitidos pela rede social de comunicação WhatsApp tem alcançado as famílias atendidas. As profissionais afirmam que essa frente de atuação tem atingido $4,5 \%$ da população de estudantes dessa unidade escolar, isto é, das/dos 552 estudantes matriculados apenas 25 vem cumprindo as atividades e tarefas diárias em constante acompanhamento com as/os docentes. Do total de estudantes, apenas 286 integram estes grupos, o que representa cerca de $51,81 \%$ do contingente do corpo discente tendo acesso às atividades propostas nos materiais - os telefones utilizados são dos responsáveis. Desse número, segundo as educadoras, tiram-se os números que não funcionam, os que já mudaram, os que não tem crédito para acessar o aplicativo ou outras redes sociais e vídeos, além do fato de por exemplo dois responsáveis por um mesmo estudante, então 286 não é um número real. Contando que outras crianças que podem estar fazendo e a família não postou dizendo que estão fazendo pode aumentar um pouco mais, mas acredito o que nem chega a 10\%. Isso não funciona! Você imagina o que é em uma escola, presencialmente, apenas $4,5 \%$ dos estudantes matriculados estarem em plena atividade? Isso é um absurdo, um descaso populacional, é desumano!

Com o passar do tempo, as Secretarias estadual e municipal de educação se posicionaram pelo uso da ferramenta Google Classroom na qual é possível armazenar tarefas, mensagens e avaliações. Os 45 professores de uma das unidades escolares estudadas foram matriculados em um curso da prefeitura sobre plataformas de Educação à Distância (EaD) intitulado: "ferramentas digitais para o trabalho remoto". Vanessa, 43 anos, professora de Revista Interinstitucional Artes de Educar. Rio de Janeiro, V. 6 - N. Especial II - p. 118-139 (jun - out 2020).127 "Educação e Democracia em Tempos de Pandemia". DOI: 10.12957/riae.2020.51907 
escola da Zona Norte e da rede há dez anos, relata em entrevista: Essa EaD jogada na nossa conta sem ter o devido preparo nem formação dos profissionais e alunos é uma tristeza.

O Sindicato Estadual dos Profissionais da Educação do Rio de Janeiro (Sepe-RJ) vem emitindo notas contrárias a essa atuação do governo, dizendo de uma implementação verticalizada, sem formação e consideração às múltiplas realidades das/dos docentes e das/dos estudantes. Tadeu, professor da rede estadual, conta: tenho achado a tecnologia fácil de manusear, pra mim tem sido tranquilo, diferente de outros professores que não estão muito habituados com essas ferramentas. A coordenação e direção tem nos acompanhado, ajudado com essas dificuldades. Elas e eles tem feito um bom trabalho conosco, mas entendo que estão enxugando gelo, também estão perdidos e sem saber o que fazer. Mas essa não é a questão, o foco tem que ser os jovens. Tenho pouco retorno dos estudantes. O resultado que temos visto na educação remota é o que esperávamos - está aumentando a desigualdade: os alunos acessam pouco, por dificuldades tecnológicas, computador e de internet mesmo, a coordenação e direção sempre indo procurar os jovens. O que chega a gente é que falta apoio material pra essa tal aula de reforço que se transformou nosso ensino público, ser eficaz. Está todo mundo sentindo.

\section{Direito fundamental em crise: para quem é possível uma educação domiciliar?}

A partir da constatação dos efeitos da adoção de uma perspectiva neoliberal na e da educação na qual o ensino remoto é colocado enquanto possibilidade, como sua concepção enquanto mercadoria e consequente privatização, o enfraquecimento da instituição escolar e a precarização do trabalho docente, chamamos atenção para outro aspecto imbricado neste fenômeno com ascensão cada vez mais expressiva: a responsabilização excessiva das/os próprias/os estudantes por sua ensinagem (FERNÁNDEZ, 2001) e, no atual contexto, também de suas famílias. Uma das diretoras, ainda no que diz respeito às/aos estudantes em processo de alfabetização, também indaga: Como podemos atribuir essa função aos estudantes e aos familiares?

Aqui, um fenômeno de nome similar que conjuga educação básica-casa-família se apresenta como um enunciado importante nesta discussão e nos auxilia a compor este jogo de forças: a educação domiciliar. Maria Celi Vasconcelos (2017) indica que o movimento homeschooling, cuja popularidade cresceu no início da década de 1980 especialmente nos Estados Unidos, se caracterizou pela oposição às leis e ao sistema de escolarização vigente e obrigatório. Como objetivo de análise, a autora coloca a 
(...) progressiva tensão entre a tendência de desescolarização, considerada decorrente de um projeto neoliberal consolidado em muitos países, e o declarado direito dos pais de decidir sobre a educação dos filhos, identificando, como consequência, a possibilidade de estes espaços - casa e escola - coexistirem na sociedade como legitimados para ensinar (VASCONCELOS, 2017, p. 125).

As produções de especialistas da área de educação, de direito e de políticas públicas fornecem subsídios para a discussão acerca da constitucionalidade da proposta e dos interesses envolvidos, assim como dos argumentos nas posições favoráveis e desfavoráveis (VASCONCELOS, 2017) - como liberdade de escolha dos pais em relação à educação de seus filhos, ausência de proibição expressa nas legislações pertinentes ao tema e falência do sistema educacional, contrapostos à influência direta de ideologias religiosas, projeto neoliberal de sociedade (OLIVEIRA; BARBOSA, 2017) e imprescindibilidade do Estado na garantia da educação enquanto direito fundamental (com possíveis efeitos de tal reconhecimento legal na retenção dos investimentos estatais na educação pública).

Álvaro Ribeiro e José Palhares (2017), por sua vez, ao apresentarem a educação domiciliar enquanto fenômeno socialmente construído em território português, indicam pistas importantes para a nossa discussão acerca da relação entre a casa como espaço possível de educação formal e as escolhas aliadas à um sistema político-econômico. Os autores propõem uma explicação para o aumento de quase $800 \%$ do número de estudantes matriculados em ensino doméstico - salto de 62, em 2012, para 564 em 2015 - relacionada às medidas resultadas do Memorando de Entendimento em relação à assistência financeira externa assegurada pelo conjunto FMI, Banco Central Europeu e União Europeia postas em prática pelo governo de Portugal no período 2011-2015, resultando no "empobrecimento de amplos sectores da população e no enfraquecimento do investimento público em sectores-chave, tais como as políticas sociais e a educação" (RIBEIRO; PALHARES, 2017, p. 64). Defendem ainda:

(...) estamos em crer que o aumento exponencial do número de famílias que optaram por educar e ensinar em casa pode ancorar na degradação das condições de vida das pessoas, sobretudo das pertencentes à classe média, cujos rendimentos foram substancialmente reduzidos e entre as quais mais incidiu o desemprego (RIBEIRO; PALHARES, 2017, p. 64-65).

A educação pública portuguesa neste período, dirigida politicamente por um governo conservador-direita, era alvo de medidas como o aumento de alunos/as por turma/classe, agrupamentos unidos através da junção de escolas de vários ciclos, demissão exponencial de professoras/es, concentração clássica de conteúdos do currículo escolar (matemática, ciências, 


\section{língua portuguesa), introdução de avaliações nacionais padronizadas e outras; desse modo,}

não é surpreendente que, com o empobrecimento da renda familiar, um número expressivo de famílias tenha optado pela educação domiciliar à matricular as/os estudantes na rede pública de ensino (RIBEIRO; PALHARES, 2017).

Semelhanças com a realidade brasileira não são meras coincidências, mas uma provocação se faz aqui imperativa: as medidas observadas em decorrência da crise portuguesa são as condições "normais" da educação brasileira há décadas. A realidade contemporânea brasileira pode ser muito bem descrita pelo educador Darcy Ribeiro (1986) quando diz que a crise educacional do Brasil, da qual tanto se fala, não é uma crise: é um projeto. Um programa em curso, cujos frutos, amanhã, falarão por si mesmos. O educador Boaventura Sousa Santos (2020), ao propor conhecimentos decorrentes da cruel pedagogia do vírus, ratifica a normalidade da exceção, de uma crise que não é passageira, o que limita a explicação de fatores que a provocam; antes, trata-se de uma crise permanente, mantida através de astúcias, artimanhas - e escolhas - cujo objetivo é não a resolver.

A partir do entendimento que coloca a educação domiciliar em termos de opção/escolha amparada na liberdade das famílias acerca do modo pelo qual as/os estudantes serão educados, propondo sua regulamentação enquanto modalidade e não como extinção da instituição escolar, questionemo-nos: quem tem liberdade para escolher quando uma crise se apresenta como imperativo? Que famílias podem conceber seus lares como opção eficaz na educação formal de suas/seus filhas/os, ou seja, responsabilizar-se por tal processo?

Como relatado em textos oficiais que versam sobre o tema no contexto brasileiro, tal pauta não é recente e tem convocado, nos últimos anos, discussões em várias esferas sociais, desde organizações da sociedade civil - como a Associação Nacional de Educação Domiciliar (ANED) e a Associação Brasileira de Defesa e Promoção da Educação Familiar (ABDPEF) ao Supremo Tribunal Federal, instância máxima do poder judiciário xiii.

Ao analisar tal fenômeno a partir das desigualdades que estruturam a produção das subjetividades brasileiras, construídas por um capitalismo neoliberal constituído a partir das artimanhas de processos crônicos como o colonialismo, o racismo e o patriarcado (SANTOS, 2020) é necessário colocar em um mesmo plano relações familiares, sociais, econômicas e políticas, na medida em que produz efeitos que longe estão de impactar somente as famílias adeptas ao movimento da educação domiciliar. Enquanto esta, se regulamentada, se apresentaria como uma espécie de autoisolamento de certas classes no contexto de distanciamento social que estamos experimentando (RIBEIRO; PALHARES, 2017), o ensino remoto posto em prática acentua o heteroisolamento já vivenciado por grupos Revista Interinstitucional Artes de Educar. Rio de Janeiro, V. 6 - N. Especial II - p. 118-139 (jun - out 2020)130 "Educação e Democracia em Tempos de Pandemia". DOI: 10.12957/riae.2020.51907 
vulnerabilizados, algo como uma quarentena permanente (SANTOS, 2020) decorrente de um sistema que é, em si, o próprio desastre (DAVIS; KLEIN, 2020), uma vez que

(...) em situações de emergência as políticas de prevenção ou de contenção nunca são de aplicação universal. São, pelo contrário, selectivas. Por vezes, são abertas e intencionalmente adeptas do darwinismo social: propõem-se garantir a sobrevivência dos corpos socialmente mais valorizados, os mais aptos e os mais necessários para a economia. Outras vezes, limitam-se a esquecer ou negligenciar os corpos desvalorizados (SANTOS, 2020, p. 27).

Neste sentido, é preciso sempre marcar e localizar a composição do corpo discente da Educação Básica pública brasileira. De acordo com dados do Censo Escolar da Educação Básica de 2019 (BRASIL, 2020e), a população negra - composta por estudantes de raça/cor preta e parda - detém maior percentual de ocupação em todas as etapas de ensino (com índices superiores a $50 \%$, apesar da quantidade não declarada), exceto pela creche - destaque para o índice de 72,5\% observado na Educação de Jovens e Adultos (EJA). Mesmo sem a análise oficial dos dados em função de renda, é possível afirmarmos que essa responsabilização tem como principais afetadas as famílias negras e empobrecidas, já expostas aos infinitos efeitos de um racismo estrutural em relação à trabalho, saúde e outros direitos fundamentais, na medida em que

(...) a desigualdade social acaba se refletindo na desigualdade escolar, não oportunizando aos estudantes as mesmas garantias de acesso e permanência. O que causa mais espécie é a visão de que a sociedade não projeta em sua juventude uma alusão ao futuro. Ao contrário, acaba por desregular um direito que é fundamental, que é a educação plena e uma gama de possibilidades para ampliar a inserção dos jovens numa sociedade mais justa e igualitária (OLIVEIRA, 2020, p. 251).

A diretora Áurea faz um breve relato da situação de desigualdade vivida em sua escola: Temos estudantes de 6 anos, estudantes que não leem em turmas de reforço escolar; os projetos de aceleração com muitas defasagens; pessoas que não têm celular; pais que tem celular, mas sem internet; pessoas que não têm computador.

Marina, 45 anos, professora na Zona Oeste do Rio de Janeiro há 19 anos, relata em entrevista uma demanda de um pai que precisa lidar com a educação remota das filhas em casa durante o isolamento social que fala por si mesmo: "Dona Marina, eu tô lá no grupo de responsáveis da turma das minhas filhas Viviane e Gabriela, do sexto ano. A senhora mandou a tarefa lá, deixa eu falar uma coisa pra senhora. Qual a posição da escola em relação à impressão desses materiais? Eu não tenho dinheiro não! Tamo sem o que comer aqui, Dona Marina. Eu só tenho um celular aqui em casa, é pré-pago. Eu preciso levar o 
celular todo dia pra trabalhar. Como é que eu faço, Dona Marina, me diz? Eu deixo meu celular com minhas filhas pra fazerem tarefa? E meu trabalho, e a comida? Fico esperando uma posição da senhora sobre isso das tarefas". A educadora se sensibiliza e expõe: eu tive vontade de chorar ao escutar aquele senhor. Tem necessidades emergenciais que estão sendo ignoradas há muito tempo no nosso país como ter água, comer. Me sinto violada por essa prefeitura e as políticas públicas de educação sendo feitas dessa forma.

Outro aspecto importante dessa responsabilização e as desigualdades que tanto a constituem como a sucedem, enunciado a partir da proposta de educação domiciliar, consiste na manutenção de um modo-indivíduo (BARROS, 2009) que coloca a desescolarização como condição na efetivação de uma aprendizagem autodirigida da/do estudante, tomando-o como centrossistema do processo educacional (RIBEIRO; PALHARES, 2017). Ao dissociar da instituição escolar a possibilidade de um processo educacional que reconheça as singularidades de cada sujeito e aposte em seu protagonismo, a ideia de educação domiciliar, na prática, alicerça interesses individualistas muito bem definidos por meio do desprezo pela competência de docentes e outros profissionais que apostam no coletivo como fonte de transformação social (ZAIDAN; GALVÃO, 2020).

Nesse sentido, contribuições do campo da Psicologia também ganham espaço na disputa de narrativas e são apropriadas de forma conveniente, enfatizando, principalmente, uma perspectiva experimental focada especificamente no processo educacional com conceitos oriundos de estudos acerca dos tipos de inteligência - confirmando ideias individualistas como, por exemplo, capital cultural.

O discurso político da meritocracia, aqui, enquanto estratégia de uma elite na produção de subjetividades individuadas e inibidor de formações coletivas, não é resultado da crise, mas é nela que encontra novos sopros de alcance, afinal, este grupo nega a "natureza de classe da crise, que, para os capitalistas, não existe, isto é, faz parte do ciclo mesmo do capital - ganham eles tanto no processo de expansão, quanto na crise" (ZAIDAN; GALVÃO, 2020, p. 274). É nesse contexto em que narrativas se constroem e são percebidas: o uso de conexões à internet de estabelecimentos comerciais, como um açougue ${ }^{\text {xiv }}$, para o acompanhamento dos conteúdos é supervalorizado enquanto estratégia construída por uma/um estudante interessado em perseguir seus sonhos, ao passo que desabafos acerca da dificuldade de concentração para estudar em casa são desprezados por formuladores das medidas e produzem culpa e medo nas/nos estudantes ${ }^{\mathrm{xv}}$, incidindo sem medidas em seu processo educacional e, em última análise, na construção de seus projetos de vida e saúde mental. 


\section{Considerações, longe de serem finais}

Boaventura de Sousa Santos (2020) enumera lições primeiras do que chama "intensa e cruel pedagogia do vírus", dentre elas o modo em que o tempo midiático e político condiciona a sociedade acerca dos riscos que esta corre e a indiscriminação apenas ilusória das pandemias quanto aos seus alvos - exceto pela determinação dos humanos enquanto únicos atingidos, justificando o pânico a partir da crise em seu modo de funcionamento de um mundo artificialmente produzido, como nos lembra o líder indígena Ailton Krenak (2020).

Seguindo suas pistas, propomos reflexões como: para além de uma pedagogia do vírus, que pedagogias esse agente nos faz ver? Que pedagogias as políticas educacionais em tempos de pandemia ensejam? As perspectivas de análise apontam para a urgência de

(...) criar um novo senso comum, a ideia simples e evidente de que sobretudo nos últimos quarenta anos vivemos em quarentena, na quarentena política, cultural e ideológica de um capitalismo fechado sobre si próprio e a das discriminações raciais e sexuais sem as quais ele não pode subsistir. A quarentena provocada pela pandemia é afinal uma quarentena dentro de outra quarentena (KRENAK, 2020, p. 32).

Partindo das realidades experienciadas por diretoras/es, coordenadoras/es e professoras/es de comunidades escolares fluminenses em decorrências das políticas educacionais adotadas no atual momento, é mais urgente que nunca se dar conta de que, como aponta Ailton Krenak (2020, p. 7), "somos piores que a COVID-19”. Em um contexto crescente de mercantilização da educação, no bojo de um Estado neoliberal e de um capitalismo colonial, racista e patriarcal, foram criadas as condições de possibilidade para fenômenos que buscam retirar do processo educacional seu caráter político, inventivo, plural e coletivo, dos quais a precarização do trabalho docente, o enfraquecimento da instituição escolar, a responsabilização das/dos estudantes - principalmente de famílias negras - e a proposta de uma educação domiciliar são enunciados.

O líder indígena ainda nos chama a atenção para um imperativo: "temos de parar de vender o amanhã" (KRENAK, 2020, p. 12), assim como permitimos o esquecimento de um passado e monetização de um presente. Nossa atenção deve se voltar para a chance de conceber alternativas de novos modos de vida, desalienados de nossa prepotência em relação à natureza e aos recursos por ela oferecidos, cujo foco seja a construção de uma outra 
normalidade, que garanta direitos fundamentais. Como afirma Valdete Souto Severo (2020, p. 223):

Há também como alterar o modo de distribuição dos recursos públicos. Impostos devem servir para garantir saúde, educação, moradia e trabalho, e não para pagar dívida pública. (...) Se não há saneamento básico, alimentação adequada, moradia decente, se não há trabalho seguro com salário digno, se não há investimento em ciência, saúde e educação, como enfrentar uma pandemia?

Ao mesmo tempo, a verticalização das medidas - impostas sem planejamento e cujo objetivo é camuflar as racionalidades que as engendram - escancara o quanto a escola é importante e o quão necessária é a construção cotidiana de uma forte comunidade escolar, próxima da realidade das famílias que a compõem. É evidente que a organização na atenção às famílias vulnerabilizadas, a análise crítica dos projetos político-pedagógicos e a construção de estratégias territorializadas, além de marcar uma política de ação e uma educação autóctone, como nos lembram os educadores populares Paulo Freire (FREIRE, 1991, 2000) e José Marí (MARTI, 1875; NASSIF, 2010), não dispensam mobilizações macropolíticas em relação aos direitos das/os profissionais, a redistribuição de recursos públicos e a construção de políticas de aprendizagem outras que não se limitem à possibilidade de obtenção da educação como um produto comprado.

Contudo, a pandemia não se mostra como oportunidade apenas para a construção dessas alternativas, mas também para a experimentação de futuras novas modelagens institucionais e existenciais calcadas nas mesmas (ir)racionalidades do neoliberalismo, como também do capitalismo e sua lógica da mercadoria (CARDOSO, 2020; DAVIS; KLEIN, 2020). É justamente no enfraquecimento dessa capacidade da educação - e da instituição escolar, importa marcar - de fazer convergir outros direitos fundamentais a partir de formações coletivas que a pandemia se mostra para as elites como oportunidade de um laboratório de engenharia social, conjugando estratégias de controle, "em escala macro e micro, combinando um controle minucioso em escala local com outro geral e extenso. (...) Em suma, eles se preparam para eventuais desafios à sua dominação" (ZIBECHI, 2020, p. 33).

É nesta disputa de oportunidades que não podemos deixar de marcar quanta potência há no espaço escolar e do quanto precisamos defendê-lo em contextos e épocas de tanto sucateamento e destruição da garantia ao direito de acesso e permanência a uma escola pública, laica e gratuita. Em um cenário nacional no qual já existe uma luta travada contra a proposta de uma Escola sem Partido, que destrói a relação professor-estudante no processo educativo colocando o/a professor/a no lugar do elemento perigoso, que precisa ser contido, 
calado e "amordaçado" para não ameaçar e contrariar a liberdade de consciência e de crença dada pela família (SANTA-BÁRBARA, CUNHA, BICALHO, 2017), precisamos problematizar também a educação domiciliar e seus efeitos nos mais diversos planos, na medida em que pretende uma educação a-d(i)versa à multiplicidade de perspectivas de construção de si e do mundo. Reconhecer a escola como um espaço no qual o controle incide sobre os corpos e subjetividades permite sua ressignificação a partir da não negação do poder operado e da ratificação do compromisso com uma educação emancipatória, de qualidade e, principalmente, que possibilita a compreensão de encontros de diferenças como aumento da potência de agir no mundo.

Educar é entendido aqui como um trabalho de conexão com a vida e a prática, pois é preciso ressignificar teorias que coloquem crianças ideais, famílias ideais, classes sociais ideais, sempre pautadas em uma representação de modos hegemônicos de ser. Quando nos deparamos cotidianamente com nossa realidade, participamos dela, somos educadores do cotidiano. Nos colocamos em uma bifurcação: hierarquizar aquela realidade em relação ao ideal, negando-a e menosprezando-a, ou lutar para romper com esses modelos aprendidos, com interesse e disposição para nos predispormos a aprender e a trabalhar com ela.

É aqui que pensamos que a psicologia pode contribuir: a criação e manutenção de espaços que levem os diversos atores escolares a questionarem e refletirem sobre as bases da escola. Vemos e apostamos na coletividade como potencial forma de superação das condições perversas e alienantes impostas pelo sistema político-econômico à educação pública. Que escola temos? Qual é o tom das relações interpessoais na escola? Que escola queremos? Quais são nossas possibilidades e limites? O que podemos fazer para construir esta escola com os nossos coletivos?

\section{Referências}

ASSOCIAÇÃO DE PÓS-GRADUANDOS DA UFRJ - APG-UFRJ. Ninguém fica pra trás: propostas e questões para debates sobre aulas remotas. Maio, 2020.

BARROS, R. B. de. Grupo: afirmação de um simulacro. 2 ed. Porto Alegre: Sulina/UFRGS, 2009.

BRASIL. Lei $n^{\circ} 11.892$, de 29 de dezembro de 2008. Institui a Rede Federal de Educação Profissional, Científica e Tecnológica, cria os Institutos Federais de Educação, Ciência e Tecnologia, e dá outras providências. 
BRASIL. Portaria n. 343, de 17 de março de 2020a. Dispõe sobre a substituição das aulas presenciais por aulas em meios digitais enquanto durar a situação de pandemia do Novo Coronavírus - COVID-19. Disponível em: $<$ http://www.in.gov.br/en/web/dou/-/portaria-n343-de-17-de-marco-de-2020-248564376>. Acesso em: 23 maio 2020.

BRASIL. Medida provisória $n$. 934, de $1^{\text {o }}$ de abril de 2020b. Estabelece normas excepcionais sobre o ano letivo da educação básica e do ensino superior decorrentes das medidas para enfrentamento da situação de emergência de saúde pública de que trata a Lei $\mathrm{n}^{\circ} 13.979$, de 6 de fevereiro de 2020. Disponível em: $<$ http://www.in.gov.br/en/web/dou//medida-provisoria-n-934-de-1-de-abril-de-2020-250710591>. Acesso em: 23 maio 2020.

BRASIL. Portaria n. 376, de 3 de abril de 2020c. Dispõe sobre as aulas nos cursos de educação profisssional técnica de nível médio, enquanto durar a situação de pandemia do novo coronavírus - Covid-19. Disponível em: $<$ http://www.in.gov.br/en/web/dou/-/portaria-n-376 -de-3-de-abril-de-2020-251289119>. Acesso em: 23 maio 2020.

BRASIL. Decreto n. 10.312, de 4 de abril de 2020d. Amplia, temporariamente, o escopo de multiprogramação com conteúdo específico destinado às atividades de educação, ciência, tecnologia, inovações, cidadania e saúde de entidades executoras de serviço de radiodifusão de sons e imagens em tecnologia digital, com fins exclusivamente educacionais ou de exploração comercial, em razão da pandemia da Covid-19. Disponível em: $<$ http://www.in. gov.br/en/web/dou/-/decreto-n-10.312-de-4-de-abril-de-2020-251139882>. Acesso em: 23 maio 2020.

BRASIL. Censo da Educação Básica 2019: Resumo Técnico. Brasília: Instituto Nacional de Estudos e Pesquisas Educacionais Anísio Teixeira (INEP), 2020e. Disponível em: $<$ http://portal.inep.gov.br/informacao-da-publicacao//asset publisher/6JYIsGMAMkW1/ document/id/6874720>. Acesso em: 25 maio 2020.

BOTELHO, P. S.; CUNHA, T. C.; BICALHO, P. P. G. de. Processos de criminalização da pobreza no território escolar. Revista Psicologia Escolar e Educacional, 2020.

CARDOSO, W. Crise é oportunidade. TOSTES, A.; MELO FILHO, H. (Org.). Quarentena: reflexões sobre a pandemia e depois. 1. ed. Bauru: Canal 6, p. 241-255, 2020.

CGI.BR. Três em cada quatro brasileiros já utilizam a Internet, aponta pesquisa TIC Domicílios 2019. 26 mai. 2020. Disponível em: https://www.cgi.br/noticia/releases/tres-emcada-quatro-brasileiros-ja-utilizam-a-internet-aponta-pesquisa-tic-domicilios-2019/. Acesso em: 12 jun. 2020.

DAVIS, A.; KLEIN, N. Construindo movimentos [recurso eletrônico]: uma conversa em tempos de pandemia. Tradução: Leonardo Marins. 1. ed. São Paulo: Boitempo, 2020.

DELEUZE, G. O mistério de Ariana. Lisboa: Ed. Vega: Passagens, 1996. FERNÁNDEZ, A. Os idiomas do aprendente: análises de modalidades ensinantes com famílias, escolas e meios de comunicação. Trad. Neusa Kern Hickel e Regina Orgler Sordi. Porto Alegre: Artmed Editora, 2001.

FREIRE, P. Pedagogia do Oprimido. Paz e Terra, 1991. 
FREIRE, P. Educação como prática de liberdade: a sociedade brasileira em transição. Rio de Janeiro, Paz e Terra, 2000.

GENTILI, P. Neoliberalismo e educação: manual do usuário. In: SILVA, T. T. da; GENTILI, P. (Orgs.). Escola S.A.: quem ganha e quem perde no mercado educacional do neoliberalismo. Brasília, DF: CNTE, 1996, p. 9-49.

GUATTARI, F. Caosmose: um novo paradigma estético. São Paulo: 34, 2006.

GUATTARI, F; ROLNIK, S. Micropolítica: Cartografias do Desejo. Petrópolis, RJ: Vozes, 2013.

IWASAKI, C.; AZEVEDO, C.; PEÇANHA, E.; ROZA, E. Educação em tempos de COVID19/Coronavírus: reflexões a partir da pesquisa sobre o uso da tecnologia nos sistemas públicos brasileiros. Metaxy, Rio de Janeiro, 2020.

KRENAK, A. O amanhã não está à venda. São Paulo: Companhia das Letras, 2020.

LOURAU, R. Análise Institucional e Práticas de Pesquisa. Rio de Janeiro: Ed. UERJ, 1993.

MARTI, J. Revista Universal, México, 1875, p. 132-135.

MORAES, M. PesquisarCOM: política ontológica e deficiência visual. MORAES, M.; KASTRUP, V. Exercícios de ver e não ver: arte e pesquisa com pessoas com deficiência visual. Rio de Janeiro: Nau Editora, p. 36-51, 2010.

NASSIF, R. José Martí. Recife: Fundação Joaquim Nabuco-Editora Massangana, 2010.

OLIVEIRA, F. L. de. Educação transformada em EAD durante a pandemia: quem e o que está por trás dessa ação? AUGUSTO, C. B.; SANTOS, R. D. dos. (Org.). Pandemias e pandemônio no Brasil. 1 ed. São Paulo: Tirant lo Blanch, p. 247-260, 2020.

OLIVEIRA, R. L. P.; BARBOSA, L. M. R. O neoliberalismo como um dos fundamentos da educação domiciliar. Pro-posições, Campinas, SP, v. 28, n. 2 (83), p. 193-212, 2017.

PASSOS, E.; KASTRUP, V.; ESCÓSSIA, L. da. (Orgs.) Pistas do método da cartografia: Pesquisa-intervenção e produção de subjetividade. Porto Alegre: Sulina, 2015.

PATTO, M. H. S. A família pobre e a escola pública: anotações sobre um desencontro. Psicol. USP, São Paulo, v. 3, n. 1-2, 1992, p. 107-121.

PATTO, M. H. S. A produção do fracasso escolar: histórias de submissão e rebeldia. 4 ed. São Paulo: Intermeios, 2015.

PAIXÃO, L. P. A escola dos carentes: um projeto em Minas Gerais. ARROYO, M. G. (Org.). Da escola carente à escola possível. 6ª ed., São Paulo: Loyola. 2003.

RIBEIRO, Á. M. C.; PALHARES, J.. O homeschooling e a crítica à escola: hibridismos e (des)continuidades educativas. Pro-posições, Campinas, v. 28, n. 2 (83), p. 57-84, 2017.

RIBEIRO, D. Sobre o óbvio. Rio de Janeiro: Guanabara, 1986. 
SANTA-BÁRBARA, I. S. M.; CUNHA, F. L.; BICALHO, P. P. G. Escola 'sem' Partido: Visibilizando racionalidades, analisando governamentalidades. In: FRIGOTTO, G. (Org.). Escola 'sem' partido: esfinge que ameaça a educação e a sociedade brasileira. 1ed. Rio de Janeiro: UERJ/LPP, v. 1, p. 105-120, 2017.

SEVERO, V. S. Sobre a COVID-19 e as nossas escolhas. TOSTES, A.; MELO FILHO, H.. (Org.). Quarentena: reflexões sobre a pandemia e depois. 1. ed. Bauru: Canal 6, p. 219-225, 2020.

TEDESCO, S. H.; SADE, C.; CALIMAN, L. V. A entrevista na pesquisa cartográfica: a experiência do dizer. In: PASSOS, E.; KASTRUP; V.; TEDESCO, S. (Orgs.). Pistas do método da cartografia: a experiência da pesquisa e o plano comum. Porto Alegre: Sulina, 310 p., v.2, 2014.

VASCONCELOS, M. C. C. Educação na casa: perspectivas de desescolarização ou liberdade de escolha? Pro-posições, Campinas, v. 28, n. 2 (83), p. 122-140, 2017.

ZAIDAN, J. de M.; GALVÃO, A. C.. COVID-19 e os abutres do setor educacional: a superexploração da força de trabalho escancarada. AUGUSTO, C. B.; SANTOS, R. D. (Org.). Pandemias e pandemônio no Brasil. 1 ed. São Paulo: Tirant lo Blanch, p. 261-275, 2020 .

ZIBECHI, R. Coronavírus: a militarização das crises. DAVIS, M. et al. Coronavírus e a luta de classes. Terra sem Amos: Brasil, p. 31-33, 2020.

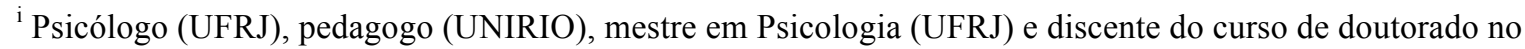
Programa de Pós-graduação em Psicologia (UFRJ). Bolsista CNPq. Professor da graduação em Psicologia da Universidade Santa Úrsula (USU), campus Botafogo e Colégio. E-mail: colmenerocunha@gmail.com. ORCID https://orcid.org/0000-0001-8202-3377
}

${ }^{\text {ii }}$ Psicóloga (UFF), mestra em Políticas Públicas e Formação Humana (UERJ) e discente do curso de doutorado no Programa de Pós-graduação em Psicologia (UFRJ). Técnica em Assuntos Educacionais (IFRJ) e professora da rede municipal do Rio de Janeiro (de 1995 a 2017). E-mail: scrivano.isabel@gmail.com. ORCID https://orcid.org/0000-0001-8203-4244

iii Psicólogo (UFRJ) e discente do curso de mestrado no Programa de Pós-graduação em Psicologia (UFRJ). Bolsista CAPES. E-mail: ericksilvieira@gmail.com. ORCID https://orcid.org/0000-0003-0317-4762

${ }^{\text {iv }}$ LESME, A. Estudantes criticam propaganda do MEC sobre o Enem 2020. Brasil Escola, em 05/05/2020. Disponível em: https://vestibular.brasilescola.uol.com.br/enem/ estudantes-criticam-propaganda-do-mec-sobre-o-enem-2020/347762.html.

${ }^{\mathrm{V}}$ Até a finalização deste escrito em 19/06/2020, 49.090 brasileiras e brasileiros já perderam suas vidas de acordo com dados oficiais - sem consideração do fenômeno da subnotificação. O número oficial de infectados no país já ultrapassa a marca de um milhão (1.038.568) e, internacionalmente, a quantidade se aproxima de 9 milhões, totalizando 460.530 óbitos.

vi Deliberação CEE $\mathrm{n}^{\circ}$ 376, de 23 de março de 2020. Disponível em: <https://anec.org.br/wpcontent/uploads/2020/03/Delibera\%C3\%A7\%C3\%A3o-CEE-n.-376.2020.pdf>.

vii Para conhecimento das ações praticadas em território nacional, consultar levantamento intitulado "Educação e coronavírus", realizado pela Vozes da Educação com apoio do Instituto Unibanco, disponível em: $<\mathrm{http}$ ://educacaoecoronavirus.com.br/consulte-o-levantamento/ $>$.

viii A partir do referencial da Esquizoanálise (GUATTARI, 2006; GUATTARI, ROLNIK, 2013), afirma-se a singularização como a ação de frustrar dispositivos de interiorização dos valores capitalísticos. Singularizar é criar pluralidade, desviar, criar, estar sensível ao caráter processual da vida. 


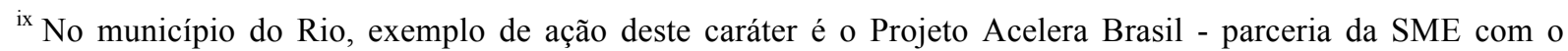
Instituto Ayrton Senna, que apresentava proposta de aceleração da aprendizagem para estudantes dos anos iniciais do ensino fundamental com dois ou mais anos de atraso escolar.

${ }^{\mathrm{x}}$ Sobre a identificação, a maioria das entrevistadas e dos entrevistados disse que era indiferente a colocar o seu nome ou um figurativo, uma vez que seria a sua história da mesma forma. Todas as pessoas entrevistadas, ficaram muito alegres de fazer parte do texto, serem personagens representantes de suas histórias singulares; fizeram questão de ser e estar aqui. Foi decidido então com elas e com eles que teriam seus nomes trocados e protegidos, cabendo-lhes a escolha de nomes fictícios.

${ }^{x i}$ Implicação aqui é utilizado a partir do referencial da Análise Institucional Francesa, na qual o sociólogo René Lourau (1993) traz a importância de colocar em análise e mapear as intensidades, as relações de poder, os afetos, as qualidades, os 'comos' das nossas presenças e intervenções, criticando uma posição distanciada, neutra, desencarnada, sem análise, do/da educador (a), pesquisador (a), da/do profissional, do indivíduo. Mais do que pensar os 'porquês' dos fatos e das ações, implicar é operar uma transformação.

${ }^{x i i}$ A MultiRio - Empresa Municipal de Multimeios - foi criada em 1993 e é vinculada à Secretaria Municipal de Educação da Prefeitura da cidade do Rio de Janeiro. Suas atribuições dizem respeito à constante atualização da educação pública, com ações no uso de meios de comunicação e recursos tecnológicos no exercício de ensinar e aprender.

xiii $\mathrm{O}$ primeiro Projeto de Lei dedicado à reivindicação do reconhecimento desta prática pela legislação brasileira data de 1994 e, até 2008, projetos com ementa semelhante foram arquivados por obterem pareceres desfavoráveis das comissões aos quais foram encaminhados quanto ao mérito das propostas. Contudo, em 2012, o PL 3179, de autoria do Deputado Lincoln Portela (PR-MG), obteve parecer favorável à sua aceitação, tendo obtido sucesso em sua tramitação inclusive por meio de apensados (PL 3261/2015 de Eduardo Bolsonaro/PSCSP e PL 10185/2018 de Alan Rick/DEM-AC) e de sua constituição como pauta do atual governo federal.

${ }^{\text {xiv }}$ REDAÇÃO PRIMEIRO IMPACTO. Menino de 13 anos usa wi-fi de açougue para poder estudar durante pandemia. Sistema Brasileiro de Televisão, 04 jun. 2020. Disponível em: $<$ https://www.sbt.com.br/jornalismo/primeiro-impacto/noticia/142747-menino-de-13-anos-usa-wifi-de-acouguepara-poder-estudar-durante-pandemia $>$.

${ }^{\mathrm{xv}}$ DALAPOLA, K. 'Já é difícil estudar na sala, imagina em casa', diz aluno de escola pública. R7 Educação, 17 mai. 2020. Disponível em: <https://noticias.r7.com/educacao/ja-e-dificil-estudar-na-sala-imagina-em-casa-dizaluno-de-escola-publica-17052020>. 